\title{
Early and late magnetic resonance imaging and neuropsychological outcome after head injury
}

\author{
JTL WILSON, KD WIEDMANN, DM HADLEY, B CONDON, G TEASDALE, \\ DN BROOKS
}

\begin{abstract}
From the Experimental Neuropsychology Laboratory, and Magnetic Resonance Imaging Unit, Institute of Neurological Sciences, Southern General Hospital, Glasgow, UK
\end{abstract}

SUMMARY Twenty five adults with closed head injury who had early magnetic resonance imaging (MRI) and computed tomography (CT) were followed up 5 to 18 months after injury. Patients were given a repeat MRI and performed a series of neuropsychological tests. They were classified by the deepest abnormality detectable on scanning. Classifications derived from early and late MRI scanning were significantly correlated. However, measures of neuropsychological outcome showed a strong correlation only with late MRI, and little or no relationship with either early MRI or early CT. Deeper abnormalities detected by late MRI were associated with poorer neuropsychological test performance; late ventricular enlargement was particularly associated with poor outcome. It is concluded that the lesions visualised by MRI are important for neuropsychological outcome, and that functionally significant abnormalities may only be fully apparent on late scanning.

The relationships between physical indices of brain damage and functional deficits are of considerable theoretical and practical importance. Closed head injury represents a particular challenge, because of its combination of diffuse and focal damage. ${ }^{12}$ Computed tomography (CT) typically shows damage in only the most severe cases, and it is now clear that Magnetic Resonance Imaging (MRI) is much more sensitive than CT. ${ }^{34}$ However, the significance for cognitive function of lesions detected by MRI has not been established.

Jenkins et al. $^{3}$ recently reported the acute CT, MRI, and clinical features of a series of 50 head injured patients, and noted that MRI detected more lesions than CT. Classification of the patients by the deepest lesion detected by MRI revealed that patients with lesions deeper in the neuraxis showed greater impairment of consciousness on admission. Twenty five of our patients have now had a series of neuropsychological tests and a repeat MRI scan. We had two aims: first, to discover if there was a relationship between the lesions visualised by MRI and neuropsychological function, specifically if the depth of the lesions correlated with psychological

Address for reprint requests: Dr J T L Wilson, Department of Psychology, University of Stirling, Stirling, FK94LA, UK.

Received 6 March 1987 and in revised form 30 September 1987. Accepted 1 October 1987 outcome, and second, to compare early and late MRI findings as correlates of neuropsychological outcome.

\section{Patients and methods}

Patients When the study commenced early MRI scans were available for 60 head injured patients. Contact was established by letter with 39 of these patients. Ten patients were children (less than 15 years of age) and they were not included in the current analysis. Two patients were too severely impaired to undergo neuropsychological testing, and two

Table 1 The distributions of age, level of consciousness on admission, post-traumatic amnesia (PTA), and interval before follow-up in the head injured patients

\begin{tabular}{lllll}
\hline Age $(y r)$ & $16-30$ & $31-45$ & $46-60$ & $61-73$ \\
\hline $\mathrm{N}$ & 10 & 4 & 5 & 6 \\
$\begin{array}{l}\text { Level of } \\
\text { consciousness }\end{array}$ & Coma & Impaired & Full \\
$\mathrm{N}$ & 7 & 15 & 3 \\
PTA (days) & $0-7$ & $8-14$ & 15 or over \\
$\mathrm{N}$ & 8 & 7 & 10 \\
Follow-up & 6 months & $\begin{array}{l}7-12 \\
\text { months }\end{array}$ & $\begin{array}{l}13-18 \\
\text { months }\end{array}$ \\
\hline $\mathrm{N}$ & 1 & 16 & 8 \\
\hline
\end{tabular}


further patients were unwilling to have repeat MRI. Twenty five adult patients (18 male) were therefore studied, 20 of whom had been included in the study described by Jenkins et $a .^{3}$ All patients had been transferred to the regional neurosurgical unit after being admitted to a primary surgical unit; seven patients had an intracranial operation. The level of consciousness on admission to hospital was assessed using the Glasgow Coma Score (GCS). ${ }^{5}$ GCS scores ranged from 15 (fully conscious) to less than 8 (coma).

Neuropsychological assessment Patients were given a structured interview to elicit background information and determine the duration of PTA. The neuropsychological test battery consisted of 12 procedures. General intellectual abilities were measured using six subtests of the Wechsler Adult Intelligence Scale (WAIS), ${ }^{6}$ three from the Verbal Scale: Similarities, Digit Span, and Vocabulary; and three from the Performance Scale: Block Design, Digit Symbol, and Object Assembly. Verbal memory and learning were assessed using two subtests of the Wechsler Memory Scale: ${ }^{7}$ Logical Memory, and Associate Learning. Visual-perceptual ability and visual memory were assessed by the Rey Figure Copy and Immediate Recall. ${ }^{8}$ A Word Fluency test ${ }^{9}$ was used to assess expressive aspects of language: patients were asked to give as many words as possible belonging to a particular category. The three categories used were animals, words (excluding proper nouns) beginning with the letter "S", and words beginning with the letter "J"; 60 seconds was allowed for each category of response. The responses were summed to give an overall score. Receptive language ability was assessed using part $\mathrm{V}$ of the Token Test. ${ }^{10}$ estimate premorbid IQ. ${ }^{11}$ The patient read aloud a list of 50
The National Adult Reading Test (NART) was used to

low frequency words with irregular spelling; the score was the number of words correctly pronounced. The NART score is highly correlated with full scale WAIS IQ, and Nelson and McKenna ${ }^{12}$ have shown that a reading test of this kind is relatively insensitive to the effects of brain atrophy.

Neuroimaging MRI was carried out in a Picker "Vista $1100 " 0.15$ Tesla resistive system operating at $6.38 \mathrm{MHz}$, and fitted with monitoring and support apparatus compatible with this magnetic field. An initial $2 \mathrm{~cm}$ thick spin echo (SE200/40) pilot image in the sagittal or coronal plane was used to determine the positions of 16 slices each $8 \mathrm{~mm}$ thick for a T2 weighted spin echo sequence (SE2200/80), and an eight slice $\mathrm{T} 1$ weighted inversion recovery sequence (IR2000/600/40) in the axial plane (figs 1 and 2). Acquisition times were 20 seconds, $9 \cdot 2$ minutes and 8.7 minutes, respectively. In selected cases additional sequences and orientations were used as thought appropriate by the radiologist but the mean examination time including computer processing was 34 minutes. Care was taken to ensure that the same sequences and slice positions were used for early and late examinations (fig 1).

CT scanning was carried out on the first 10 patients with an EMI 1010 head unit, producing $1 \mathrm{~cm}$ thick axial scans, and taking 15 minutes. Subsequent patients were imaged in a Philips tomoscan 310 with $6 \mathrm{~mm}$ thick axial sections taking 20 minutes. When necessary patients were ventilated and their cardiorespiratory state monitored with conventional apparatus.

All cases had an initial MRI scan within 21 days of injury, and $22(88 \%)$ within 7 days (median 3 days). Early CT scans were available for 23 patients.
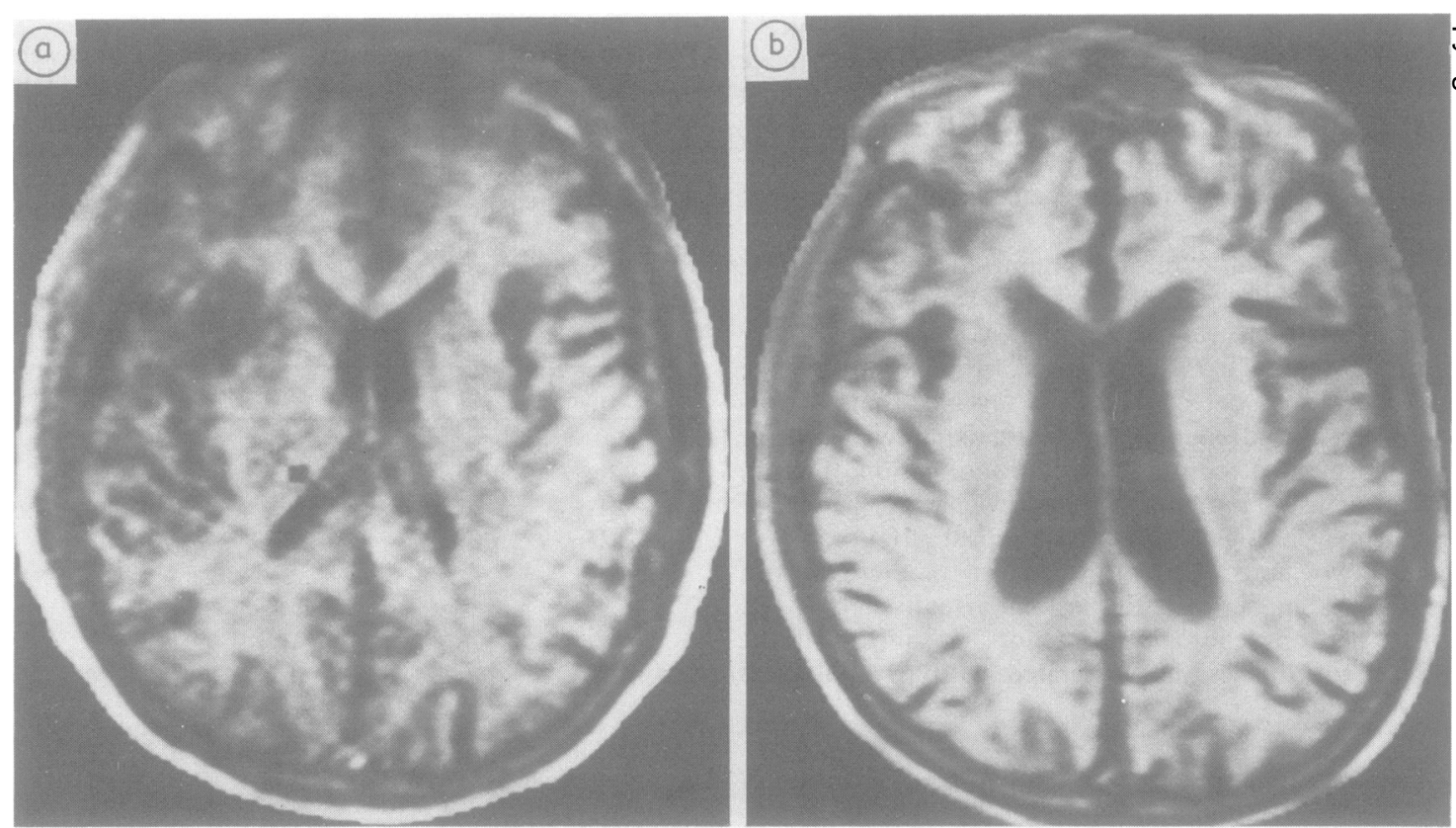

Fig 1 TI weighted (IR 2000/600/40) axial slices through the lateral ventricles (a) in the acute phase and (b) at 11 months showing the development of ventricular enlargement and cortical atrophy. 

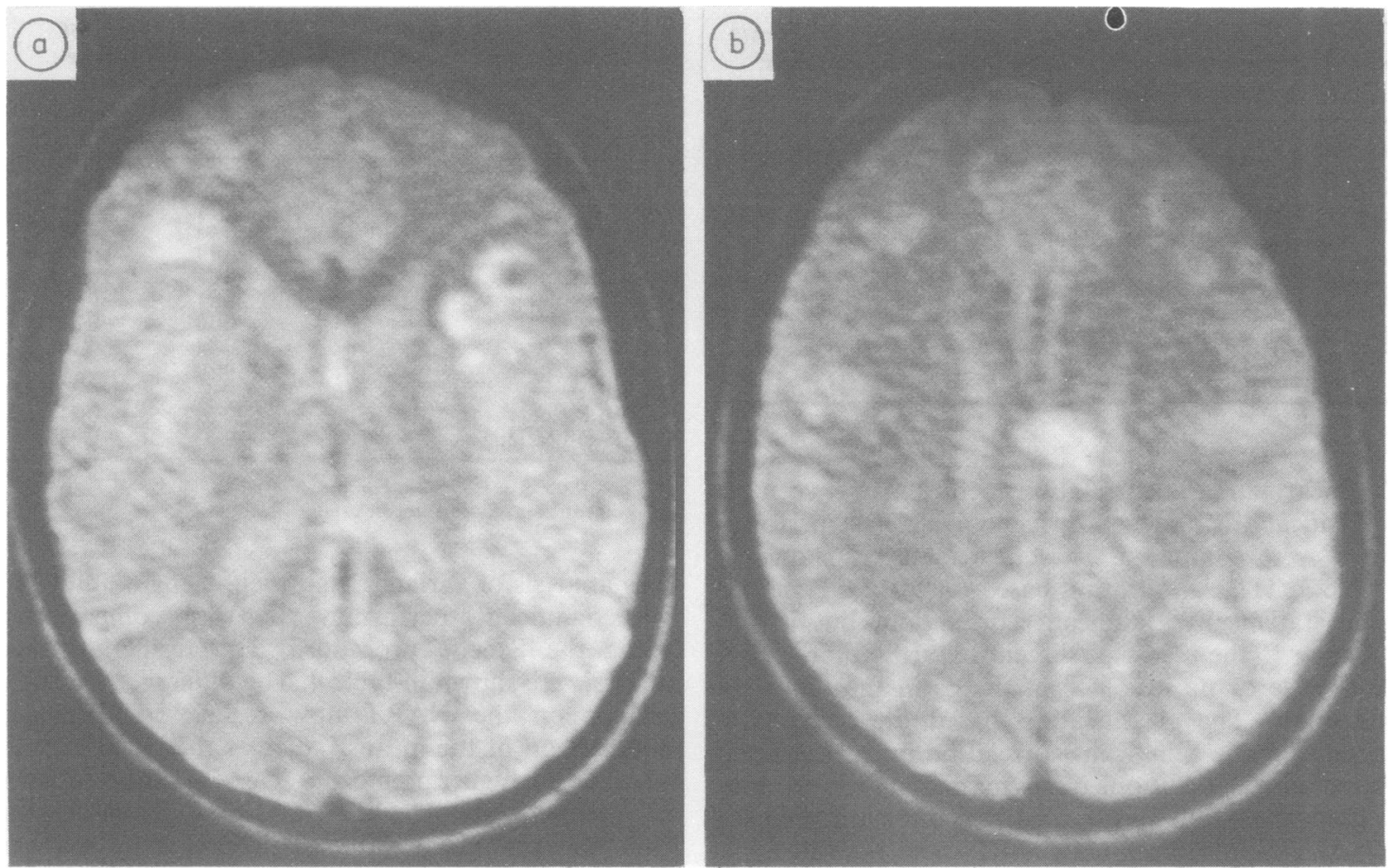

Fig $2 T 2$ weighted (SE 2200/80) axial slices in the acute phase showing (a) cortical and subcortical contusions and (b) a deep white matter corpus callosum lesion.

The scans were reviewed, and abnormalities tabulated for each patient, independently by an experienced neuroradiologist. The neuroradiologist had no access to neuropsychological test information on the patients or to patient details other than age. Early and late scans were rated at the same time; however, each scan was reported independently and in no particular order. For comparison with the neuropsychological test results each patient was assigned to one of four groups according to the deepest abnormality detected: (1) No parenchymal abnormality; this group included patients with an extracerebral haematoma. (2) Cortical abnormalities only. (3) Subcortical white matter abnormalities (in addition to any cortical abnormalities). (4) Deep white matter lesions or late ventricular enlargement consistent with atrophy (in addition to any other abnormalities). Ventricular enlargement was judged by visual inspection and was by comparison with the expected size for a person of that age. Patients were classified on the basis of each of the scans: early CT, early MRI, and late MRI.

\section{Results}

Patients were followed up between 5 and 18 months after injury (median 11 months). To assess the effect of time since injury the patients were subdivided at the median into 11 tested less than 11 months after injury and 14 tested at 11 months or later, and the groups were compared using $t$ tests. There were no significant differences between the groups on any of the neuropsychological measures, or any variable such as duration of PTA, GCS score on admission, age, localisation of lesion etc. For the purposes of further analysis the two groups were therefore combined.

The numbers of patients in each of the categories derived from the scans are shown in table 2 . In order to compare the findings from early and late MRI scans the classifications of individual patients are shown graphically in fig 3 . The Spearman rank correlation between early and late MRI categories was significant, $r=0.49, p<0.01$. Thirteen patients were in the same category on both scans, 11 differed by one category, and one patient differed by three categories. The classification derived from CT scanning correlated significantly with that from early MRI, $r=0.38, p<0.05$, but not late MRI, $r=0.16$.

In order to assess the possible contribution of premorbid IQ and age to the results the groups were compared using one way analysis of variance. Comparison of the four groups of patients by this method for each of the scans in turn showed that there were no significant differences between groups for either NART score or age. The only difference which approached significance was for the NART scores of the groups classified by late MRI, $F(3,21)=2 \cdot 94$, $p>0.05$. 
Table 2 Patients were assigned to a category on the basis of the deepest abnormality detected on each of the scans. The table shows the number of patients in each category

\begin{tabular}{|c|c|c|c|}
\hline $\begin{array}{l}\text { Deepest } \\
\text { abnormality }\end{array}$ & $\begin{array}{l}\text { Early } C T \\
(N=23)\end{array}$ & $\begin{array}{l}\text { Early MRI } \\
(N=25)\end{array}$ & $\begin{array}{l}\text { Late } M R I \\
(N=25)\end{array}$ \\
\hline \multirow{3}{*}{$\begin{array}{l}\text { (1) No parenchymal } \\
\text { abnormality } \\
\text { (2) Cortical lesion } \\
\text { (3) Subcortical white } \\
\text { matter lesion } \\
\text { (4) Deep white matter } \\
\text { lesion, or ventricular } \\
\text { enlargement }\end{array}$} & $\begin{array}{r}12 \\
2\end{array}$ & $\begin{array}{l}2 \\
6\end{array}$ & $\begin{array}{l}5 \\
3\end{array}$ \\
\hline & 8 & 10 & 5 \\
\hline & 1 & 7 & 12 \\
\hline
\end{tabular}

Spearman rank correlation coefficients between the classifications and neuropsychological test performance were computed. The coefficients are shown in table 3 . The classification based on early CT yielded one statistically significant correlation, but it was counter to the predicted direction; furthermore, there was little or no evidence of trends in the predicted direction. The classification based on early MRI produced one significant correlation in the predicted direction; in addition, other measures showed nonsignificant trends in the predicted direction. For the classification based on late MRI, there were statistically significant correlations for 11 of the 12 measures.

The relationship between the results of scanning and neuropsychological test performance is strongest for late MRI. Further analysis therefore concentrated on the subgroups based on late MRI. Subgroups (2) (cortical lesions), and (3) (subcortical white matter lesions), contained only small numbers of patients; these subgroups were therefore combined. The means and standard deviations for the neuropsychological measures for the three resulting groups are shown in table 4 . The groups were compared by first using one-

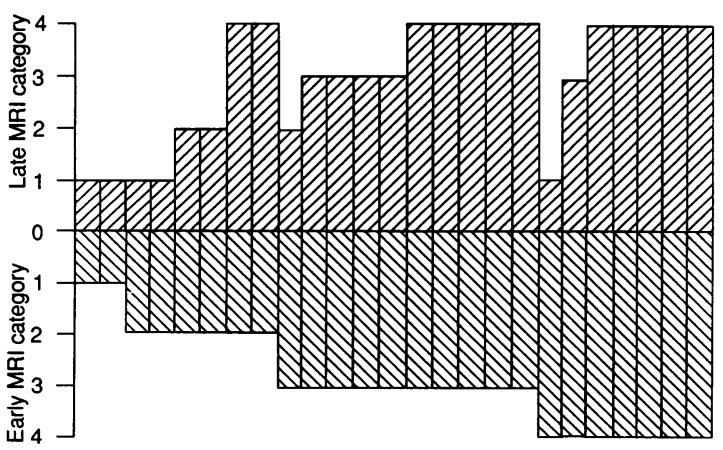

Fig 3 Classifications of individual patients on early and late MRI scans. The patients are grouped by their category on early scanning.
Table 3 Spearman correlation coefficients between the classifications and neuropsychological test performance

\begin{tabular}{lccc}
\hline Test & $\begin{array}{c}\text { Early CT } \\
(N=23)\end{array}$ & $\begin{array}{l}\text { Early MRI } \\
(N=25)\end{array}$ & $\begin{array}{l}\text { Late MRI } \\
(N=25)\end{array}$ \\
\hline Similarities & 0.25 & -0.24 & $-0.58 \ddagger$ \\
Digit Span & -0.14 & -0.21 & -0.24 \\
Vocabulary & -0.13 & $-0.43^{*}$ & $-0.48 \dagger$ \\
Digit Symbol & 0.28 & -0.14 & $-0.73 \ddagger$ \\
Block Design & -0.07 & -0.21 & $-0.86 \ddagger$ \\
Object Assembly & 0.21 & -0.21 & $-0.73 \ddagger$ \\
Rey Copy & $0.44^{*}$ & -0.10 & $-0.50 \dagger$ \\
Rey Recall & 0.32 & 0.04 & $-0.58 \ddagger$ \\
Word Fluency & 0.01 & -0.26 & $-0.56 \dagger$ \\
Token Test & 0.16 & 0.03 & $-0.40^{*}$ \\
Logical Memory & -0.08 & -0.09 & $-0.51 \dagger$ \\
Associate Learning & 0.32 & -0.02 & $-0.53 \dagger$ \\
\hline
\end{tabular}

$*=p<0.05, \dagger=p<0.01, \ddagger=p<0.001$.

$\S$ Significant correlation not in predicted direction.

way analysis of variance, and then, if the omnibus $F$ was significant, performing pairwise comparisons using the Scheffe procedure. The results of this analysis are shown in table 4 . The difference between groups on the NART now reaches significance; comparison of the means indicates that this is attributable to a higher premorbid IQ in the group with no parenchymal abnormalities, Group A. However, as can be seen from table 4, there were reliable differences between the groups with detectable abnor malities, groups B and C.

Ventricular enlargement consistent with atrophye was present in the late MRI of 11 patients and abseng in 14. Patients with ventricular enlargement had? significantly longer PTA (five patients had PTA $\overrightarrow{0}$ exceeding 1 month) than those without (one patient $\infty_{\infty}$ with PTA longer than 1 month), $t=2 \cdot 30, d f=23$, $p<0.05$. Patients with enlargement were also significantly older (mean age 49.5 years) than those without (mean age 33.8 years), $\mathrm{t}=2 \cdot 12, \mathrm{df}=23$, $\mathrm{p}<0.05$. Differences between patients with and without ventricular enlargement were assessed using analysis of co-variance, correcting for age and NART scores. There were significant main effects on seven of the 12 measures: Similarities, $F(1,21)=4.95$, $p<0.05$; Vocabulary, $F(1,21)=5.54 ; p<0.05$; Digit Symbol, $F(1,21)=11.58, \mathrm{p}<0.01$; Block Design, $\mathrm{F}(1,21)=18.42, \quad \mathrm{p}<0.01 ; \quad$ Object Assembly, $\mathrm{F}(1,21)=7.90, \quad \mathrm{p}<0.01 ; \quad$ Word Fluency, $F(1,21)=8.70, \quad p<0.01 ; \quad$ Associate Learning $F(1,21)=4.60, p<0.05$. Thus the presence of ventricular enlargement on late MRI was associated strongly with poorer test performance.

The early and late MRI findings were examined with respect to lateralisation of lesions. On early MRI there were 11 patients with unilateral lesions, seven right sided and four left sided, while on late MRI there were 10 such patients, nine right and one left. As might be expected with the relatively small numbers of 
Table 4 Means and standard deviations (in brackets) of the neuropsychological test scores for the groups based on late MRI. The results of overall significance testing and pairwise comparisons between means are also shown

\begin{tabular}{|c|c|c|c|c|c|c|}
\hline Test & $F$ & 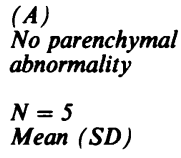 & $A v s B$ & $\begin{array}{l}\text { (B) } \\
\text { Cortical lesion or } \\
\text { subcortical white } \\
\text { matter lesion } \\
N=8 \\
\text { Mean (SD) }\end{array}$ & Bvs $C$ & $\begin{array}{l}\text { (C) } \\
\text { Deep white matter } \\
\text { lesion, or ventricular } \\
\text { enlargement } \\
N=12 \\
\text { Mean (SD) }\end{array}$ \\
\hline $\begin{array}{l}\text { Similarities } \\
\text { Digit Span } \\
\text { Vocabulary } \\
\text { Digit Symbol } \\
\text { Block Design } \\
\text { Object Assembly } \\
\text { Rey Copy } \\
\text { Rey Recall } \\
\text { Word Fluency } \\
\text { Token Test } \\
\text { Logical Memory } \\
\text { Associate Learning } \\
\text { NART }\end{array}$ & $\begin{array}{l}6 \cdot 2 \dagger \\
1 \cdot 1 \mathrm{~ns} \\
8 \cdot 3 \dagger \\
14 \cdot 9 \ddagger \\
16 \cdot 3 \ddagger \\
14 \cdot 5 \ddagger \\
2.1 \mathrm{~ns} \\
6 \cdot 9 \dagger \\
7 \cdot 9 \dagger \\
2.9 \mathrm{~ns} \\
4 \cdot 1^{*} \\
5 \cdot 8 \dagger \\
4.6^{*}\end{array}$ & $\begin{array}{l}16.6(3.3) \\
12.8(1.3) \\
63.8(7.8) \\
53.6(8.7) \\
39.0(6.8) \\
33.0(3.4) \\
36.0(0) \\
22.3(7.1) \\
39.6(10.3) \\
20.8(0.5) \\
16.9(2.5) \\
16.3(2.5) \\
33.8(6.1)\end{array}$ & $\begin{array}{l}\text { ns } \\
+ \\
\text { ns } \\
\text { ns } \\
\text { ns } \\
\text { ns } \\
\text { ns } \\
\text { ns } \\
\text { ns } \\
*\end{array}$ & $\begin{array}{l}14.0(2.6) \\
11.6(1.7) \\
39.1(11.6) \\
45 \cdot 1(13.3) \\
32.8(6.8) \\
30.8(5.7) \\
34.0(2.7) \\
15.4(7.9) \\
40.9(8.4) \\
18.8(2.0) \\
11.9(4.1) \\
15.8(3.5) \\
20.0(9.6)\end{array}$ & $\begin{array}{l}* \\
\text { ns } \\
\vdots \\
\vdots \\
\vdots \\
\text { ns } \\
\dagger \\
\text { ns } \\
* \\
\text { ns }\end{array}$ & $\begin{array}{l}10.7(3.8) \\
10.9(2.9) \\
37.4(14.6) \\
27.8(7.2) \\
20.7(6.5) \\
17.8(7.6) \\
30.5(7.4) \\
9.4(5.5) \\
25.8(9.2) \\
17.8(3.0) \\
10.4(4.9) \\
11.1(4.0) \\
21.9(8.4)\end{array}$ \\
\hline
\end{tabular}

$*=p<0.05, \dagger=p<0.01, \ddagger=p<0.001$.

patients there were no significant difference between patients with left and right sided lesions on any of the neuropsychological measures.

\section{Discussion}

The results show that there is a clear relationship between the depth of abnormality detected by followup MRI after head injury and neuropsychological test performance. The significant correlations were not simply due to the inclusion of a group without detectable brain damage: there were systematic differences within the subgroups of patients with detectable abnormalities.

The results show a pattern of correlations in which some neuropsychological tests were more strongly associated with neuroimaging abnormalities than others. The Performance measures of the WAIS, Digit Symbol, Block Design, and Object Assembly, showed particularly strong correlations with neuroimaging abnormalities. This is consistent with previous findings that scores on the Performance measures from the WAIS remain particularly depressed after injury. ${ }^{13}$ The Performance measures are all timed tests, and the present results thus suggest that deeper abnormalities may be associated with slower information processing in head injured patients.

CT is less sensitive to early abnormalities than MRI. ${ }^{3}$ Classification of patients on the basis of early CT did not yield significant correlations in the predicted direction. CT had detected abnormalities in 11 patients, while early MRI detected abnormalities in 23. Ventricular enlargement on late CT scanning is reported to correlate with poor neuropsychological test performance, ${ }^{14} 1^{15}$ and it remains to be discovered how late CT and MRI compare. A potential advan- tage of MRI over CT in studying changes in intracranial volumes after head injury is that it has recently become technically possible to measure ventricular and extraventricular cerebrospinal fluid volumes to a high degree of accuracy; ${ }^{16}$ this could be done in a future study.

The results show that depth of lesion detected by MRI is correlated with psychological impairment. This finding supports the proposal made by Ommaya and Gennarelli ${ }^{17}$ that deeper abnormalities are associated with greater structural and functional impairment after head injury, and is consistent with previous reports concerning the relationship between depth of abnormality and neurological and neuropsychological outcome. ${ }^{18-20} \mathrm{~A}$ number of lines of evidence suggest that deeper abnormalities are indicative of more widespread brain damage. On early MRI all, or nearly all, patients with intracerebral lesions have cortical lesions, while the converse is not the case. ${ }^{3}$ Furthermore, some deep lesions, for example in the corpus callosum, may be evidence of diffuse axonal damage. ${ }^{2}$ Finally, late ventricular enlargement after head injury is thought to represent predominantly the consequences of diffuse loss of tissue. ${ }^{21}$ The present results thus suggest that depth of abnormality detected by MRI represents an index of the severity of overall diffuse damage.

The relationship between MRI and outcome was much stronger for late MRI than early MRI. Although outcome could not be reliably predicted on the basis of the early scans, lesions detected in the first week after injury may well have a bearing on neuropsychological outcome. All but two of the eleven patients with ventricular enlargement at follow up had intracerebral lesions on early MRI. There was, however, a great deal of variability in the individual 
recoveries made by patients. Indeed the difference between early and late MRI as predictors of outcome can be related to the discrepancy between the early and late MRI scans themselves. For example, one patient with deep abnormalities on early scanning had a normal scan on follow up, while two patients with early subcortical white matter lesions had developed significant atrophy by the time they were imaged again (fig 3). The present results indicate that the abnormalities which are neuropsychologically significant may only be fully apparent some time after injury.

One of the central puzzles of head injury is why there should be variability in the recovery from injuries that appear clinically similar. The present results point to gradations in injury and to possible distinctions between different forms of diffuse damage. Thus, for example, diffuse damage from hypoxia-ischaemia is predominantly cortical. Contrasts should be sought between primary shearing injuries and secondary ischaemic damage, and we consider that serial MRI investigations of head injured patients are a priority for future research.

This research was supported by the Medical Research Council.

\section{References}

1 Strich SJ. Shearing of nerve fibres as a cause of brain damage due to head injury. A pathological study of twenty cases. Lancet, 1961;ii:443-8.

2 Adams JH, Graham DI, Murray LS, Scott G. Diffuse axonal injury due to nonmissile head injury in humans: An analysis of 45 cases. Ann Neurol 1982;12:557-63.

3 Jenkins A, Teasdale G, Hadley MDM, MacPherson P, Rowan JO. Brain lesions detected by magnetic resonance imaging in mild and severe head injury. Lancet, 1986;ii:445-6.

4 Snow RB, Zimmerman RD, Gandy SE, Deck MDF. Comparison of magnetic resonance imaging and computed tomography in the evaluation of head injury. Neurosurgery 1986;18:45-52.

5 Teasdale G, Murray G, Parker L, Jennett B. Adding up the Glasgow Coma Score. Acta Neurochirurgica 1979;Suppl. 28, Vol. 1:161-4.

6 Wechsler D. Manual for the Wechsler Adult Intelligence Scale. New York: Psychological Corporation, 1955.

7 Wechsler D. A standardized memory scale for clinical use. $J$ Psychol 1945;19:87-95.

8 Rey A. L'examen psychologique dans le cas d'encéphalopathie traumatique. Archives de Psychologie 1941;112:286-340.

9 Borokowski JG, Benton AL, Spreen O. Word fluency and brain damage. Neuropsychologia 1967;5:135-40.

10 De Renzi E, Vignolo LA. The token test: a sensitive test to detect receptive disturbances in aphasics. Brain 1962;85:665-78.

11 Nelson HE, O'Connell A. Dementia: The estimation of premorbid intelligence levels using the New Adult Reading Test. Cortex 1978;14:234-44.

12 Nelson HE, McKenna $P$. The use of current reading ability in the assessment of dementia. B J Soc Psychol 1975;14:259-67.

13 Mandleberg IA, Brooks DN. Cognitive recovery after severe head injury 1 . Serial testing on the Wechsler Adult Intelligence Scale. J Neurol Neurosurg Psychiatry 1975;38:1121-6.

14 Cullum CM, Bigler ED. Ventricle size, cortical atrophy, and relationship with neuropsychological status in closed head injury: a quantitative analysis. J Clin Exp Neuropsychol 1986;8:437-52.

15 Meyers CA, Levin HS, Eisenberg HM, Guinto FC. Early versus late lateral ventricular enlargement following closed head injury. J Neurol Neurosurg Psychiatry 1983;46:1092-7.

16 Condon B, Patterson J, Wyper D, Hadley D, Grant R, Teasdale $\square$ $\mathrm{G}$, Rowan J. Use of magnetic resonance imaging to measure $\bar{\omega}$ intracranial cerebrospinal fluid volume. Lancet 1986;i:1355-6.

17 Ommaya AK, Gennarelli TA. Cerebral concussion and traumatic unconsciousness. Correlation of experimental and clinical $\varrho$ observations on blunt head injuries. Brain 1974;97:633-54.

18 Levin HS, Grossman RG, Rose JE, Teasdale G. Long-term neuropsychological outcome of closed head injury. Neurosurg 1979;50:412-22.

19 Sichez-Auclair N, Sichez JP. Profils neuropsychologiques et mentaux dans les lésions encéphalique diffuses posttraumatiques sévères. 103 cas. Neurochirurgie 1986;32:63-73.

20 van Dongen KJ, Braakman R. Late computed tomography in survivors of severe head injury. Neurosurgery 1980;7:14-22.

21 Levin HS, Meyers CA, Grossman RG, Sarwar M. Ventricular enlargement after closed head injury. Arch Neurol 1981;38:623-9. 